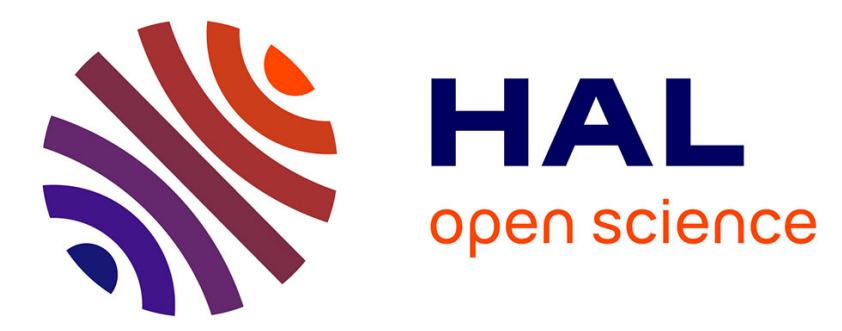

\title{
Sintered molybdenum for a metallized ceramic substrate packaging for the wide-bandgap devices and high temperature applications
}

Bassem Mouawad, Cyril Buttay, Maher Soueidan, Hervé Morel, Vincent Bley, D. Fabregue, Florian Mercier

\section{To cite this version:}

Bassem Mouawad, Cyril Buttay, Maher Soueidan, Hervé Morel, Vincent Bley, et al.. Sintered molybdenum for a metallized ceramic substrate packaging for the wide-bandgap devices and high temperature applications. ISPSD, Jun 2012, Bruges, Belgium. pp.295-298, 10.1109/ISPSD.2012.6229081 . hal-00707820

\section{HAL Id: hal-00707820 \\ https://hal.science/hal-00707820}

Submitted on 13 Jun 2012

HAL is a multi-disciplinary open access archive for the deposit and dissemination of scientific research documents, whether they are published or not. The documents may come from teaching and research institutions in France or abroad, or from public or private research centers.
L'archive ouverte pluridisciplinaire HAL, est destinée au dépôt et à la diffusion de documents scientifiques de niveau recherche, publiés ou non, émanant des établissements d'enseignement et de recherche français ou étrangers, des laboratoires publics ou privés. 


\section{Sintered molybdenum for a metallized ceramic substrate packaging for the wide- bandgap devices and high temperature applications}

\author{
Bassem MOUAWAD, Cyril BUTTAY, Maher \\ SOUEIDAN, Hervé MOREL \\ Ampère, UMR 5005 \\ Université de Lyon, INSA de lyon \\ 21 Av. J. Capelle 69621 Villeurbanne, France \\ bassem.mouawad@insa-lyon.fr, \\ cyril.buttay@insa-lyon.fr, maher.soueidan@insa- \\ lyon.fr, herve.morel@insa-lyon.fr
}

\author{
Vincent BLEY \\ LAPLACE \\ UPS, INPT \\ 118 route de Narbonne 31062 Toulouse, France \\ vincent.bley@1aplace.univ-tlse.fr \\ Damien FABREGUE \\ Mateis, UMR 5510 \\ Université de Lyon, INSA de lyon \\ 7 Av. J. Capelle 69621 Villeurbanne, France \\ damien.fabregue@insa-lyon.fr
}

\begin{abstract}
Silicon Carbide (SiC) is a good candidate for high temperature power electronic applications. To ensure good reliability, packaging materials with a coefficient of thermal expansion (CTE) matching that of $\mathrm{SiC}$ are needed. A metallized ceramic substrate based on aluminium nitride (AIN) and molybdenum (Mo) is reported in this paper. This substrate is built using a spark plasma sintering equipment. Results show that a dense Mo layer can be sintered on an AIN plate, with good adhesion, forming a Mo/AIN/Mo structure with well-matched CTES.
\end{abstract}

Keywords-Wide-bandgap devices; aluminium nitride; molybdenum; Spark Plasma Sintering

\section{INTRODUCTION}

Wide-bandgap semiconductors devices, such as silicon carbide $(\mathrm{SiC})$, have pushed the boundaries in terms of power density, conversion efficiency or switching speed compared to silicon [1]. In particular, $\mathrm{SiC}$ devices can operate at much higher temperature [2]. These devices are assembled into modules, which provide electrical interconnects, thermal management (by using a metallized ceramic substrate, a heatspreader and a heat sink) and electrical insulation (provided by the ceramic layer of the substrate). However, this package, which comprises many different materials (ceramic, metals, organic materials...) with vastly different Coefficients of Thermal Expansion (CTE), is very sensitive to thermal cycling. Indeed, any change in the operating temperature will result in a variation of the mechanical stresses experiences at the various interfaces. Repetitive temperature variations (thermal cycling conditions), and the associated stress changes, are a source of mechanical fatigue, which can lead to failure of the package.

With the extended temperature range (and therefore with the extended thermal cycling) permitted by SiC devices, the package becomes a limiting factor, and new technologies must be proposed to achieve more robust modules [3].

\section{PACKAGING}

\section{A. Metallized ceramic substrate}

In this paper, we focus on a specific part of the package, namely on the metallized ceramic substrate. This substrate concentrates many of the challenges described above: it has a large surface (usually in the order of around $10 \sim \mathrm{cm}^{2}$ ), associates materials with different CTEs (a ceramic and a metal), and must provide good electrical conductivity (of the metal layer) and thermal conductivity (of the metal and ceramic layers).

The most substrate used in conventional packaging is the Direct Bonded Copper (DBC). The DBC is formed by a ceramic layer (Aluminium oxide $-\mathrm{Al}_{2} \mathrm{O}_{3}$ - or aluminium nitride -AlN-) between two copper layers. This DBC structure leads to a high differential stress due to the materials CTE mismatch that may cause failure at high temperature [4] (see table below).

\section{B. Materials}

Some of the materials found in a high temperature power module are listed in Table I, along with their thermal properties Recently, aluminium nitride, which has CTE properties very close to that of $\mathrm{SiC}$, was proposed as a substrate material for high-temperature device packaging [5-7]. A gold thick-film metallization on AlN ceramic-based $500{ }^{\circ} \mathrm{C}$ packaging for $\mathrm{SiC}$ devices has been demonstrated [8]. The electrical interconnection system of this approach has been tested in air environment for over $5000 \mathrm{~h}$ at $500{ }^{\circ} \mathrm{C}$ and a packaged $\mathrm{SiC}$ test device operated for over $1000 \mathrm{~h}$. Other approaches found in the literature include a molybdenum (Mo) thick film metallization performed by screen printing of molybdenum-manganese paste on AIN and tungsten (W) thin film metallization sputtered on AlN with a proprietary adhesion enhancer (i.e. Titanium (Ti)) since W does not adhere to AlN [9]. The adhesive strength for both, Mo and W 
TABLE I. THERMAL PROPERTIES OF DIFFERENT MATERIALS OF A POWER ELECTRONIC MODULE [9]

\begin{tabular}{|l|c|c|}
\hline \multirow{2}{*}{\multicolumn{1}{|c|}{ Materials }} & \multicolumn{2}{|c|}{ Thermal properties } \\
\cline { 2 - 3 } & $\boldsymbol{C T E}\left(\boldsymbol{x} \mathbf{1 0 ^ { - 6 }} /{ }^{\circ} \boldsymbol{C}\right)$ & $\begin{array}{c}\text { Thermal conductivity } \\
(\boldsymbol{W} / \boldsymbol{m} . \boldsymbol{K})\end{array}$ \\
\hline Copper $(\mathrm{Cu})$ & 17 & 398 \\
\hline Molybdenum $(\mathrm{Mo})$ & 4.8 & 138 \\
\hline Tungsten $(\mathrm{W})$ & 4.5 & 178 \\
\hline Gold $(\mathrm{Au})$ & 14 & 315 \\
\hline Aluminium Oxide $\left(\mathrm{Al}_{2} \mathrm{O}_{3}\right)$ & 7.2 & 25 \\
\hline Silicon Carbide $(\mathrm{SiC})$ & 3.7 & 300 \\
\hline Aluminium Nitride $(\mathrm{AlN})$ & 4.1 & 200 \\
\hline
\end{tabular}

metallizations, was found to be $87 \mathrm{MPa}$ and $84 \mathrm{MPa}$ respectively after a heat treatment of $1100{ }^{\circ} \mathrm{C}$ for $30 \mathrm{~min}$.

As with these technologies, the work described here focuses on replacing the metallized ceramic substrate used in conventional packaging systems to a new one that will be able to withstand thermal cycling.

\section{Molybdenum / AlN}

As discussed in the last section, for the high temperature operation (and wide-range thermal cycling), both the ceramic and the metal layers need to have a CTE close to that of the $\mathrm{SiC}$ devices. Mo was found to be a promising candidate for high temperature metallized ceramic substrate and has many good advantages: (i) similar CTE to $\mathrm{AlN}$ and $\mathrm{SiC}\left(4.8 \times 10^{-6} /{ }^{\circ} \mathrm{C}\right.$ for Mo vs. $4.1 \times 10^{-6} /{ }^{\circ} \mathrm{C}$ for $\mathrm{AlN}$ vs. $3.7 \times 10^{-6} /{ }^{\circ} \mathrm{C}$ for $\mathrm{SiC}$, see table I), (ii) good adhesion material, (iii) relatively low cost, (iv) it is widely used in electrical contact for high temperature. The disadvantages are: (i) it is very difficult in achieving full densification and (ii) very difficult to assembly with AIN without any additives using standard solution [9]. Preliminary results in the densification of pure Molybdenum shows that a full densification can be obtained using a new sintering technique such as Spark Plasma Sintering [10]. We suggest to use the same sintering technique to realize both molybdenum powder sintering, and Mo / AlN layers bonding simultaneously.

\section{EXPERIMENTAL PROCEDURE}

\section{A. Spark plasma sintering}

As with a classical sintering press, a Spark Plasma Sintering (SPS) system applies both pressure and heat to samples. The difference is that the heat is provided by a pulsed DC-current circulating through a graphite die (or through the sample if it is conductive), whereas the conventional sintering press uses external heating elements. SPS offers rapid sintering, with ramps of up to $700{ }^{\circ} \mathrm{C} / \mathrm{min}$ using current pulses of several $\mathrm{kA}$. This has great potential for achieving fast densification results with minimal grain growth in a short sintering time.

The experiments were carried out in a SPS FCT systeme $\mathrm{GmbH}$, HP D 25 model. This apparatus consists of a uniaxial press with a maximum force of $250 \mathrm{kN}$ and a power supply capable of producing a pulsed current DC-current with a maximum of $8000 \mathrm{~A}$ at $8 \mathrm{~V}$.

\section{B. Samples preparation}

Commercial Molybdenum powder (Goodfellow, Cambridge, UK, $99.99+\%$ purity) with a particle size ranging from $55 \mu \mathrm{m}$ to $355 \mu \mathrm{m}$ was consolidated using SPS technique. In this technique, molybdenum powders were poured directly, with no special treatment into the cylindrical graphite die of SPS without any additive or binder.

For the ceramic layer, disks of $19,8 \mathrm{~mm}$ in diameter were laser-cut into commercial plates of AlN with two different thicknesses $(633 \mu \mathrm{m}$ and $1270 \mu \mathrm{m})$. The disks were cleaned using (i) ultrasonic cleaning in acetone, (ii) ultrasonic cleaning in microelectronic grade ethanol, (iii) immersion in $\mathrm{H}_{2} \mathrm{SO}_{4}: \mathrm{H}_{2} \mathrm{O}_{2}$ (1:1) to ensure non-existent of any metal particles (iv) followed by rinsing in DI water and blow drying with nitrogen gas.

Two sets of experiments were performed. The first set focussed on the molybdenum sintering parameters, and no AlN disks were used, Molybdenum powder samples of $20 \mathrm{~mm}$ in diameter and around $2 \mathrm{~mm}$-thick were sintered in vacuum $\left(10^{-2}\right.$ Torr $)$, without any additives. The second set of experiments was targeted at the Mo/AlN assembly. The $19,8 \mathrm{~mm}$ disks of AlN were put in 20 or $40 \mathrm{~mm}$ diameter graphite dies, and covered with a $1 \mathrm{~mm}$-thick layer Mo powder. These samples were also sintered in vacuum $\left(10^{-2}\right.$ Torr).

Precise density measurements of the consolidated bulk molybdenum samples were made using the Archimedes' principle according to ASTM Standard B328-94. The relative density was calculated based on the theoretical density of Mo $\left(10.22 \mathrm{~g} / \mathrm{cm}^{3}\right)$.

At the end of each experiment, the samples were crosssectioned, mounted in a hot mounting resin (Presi Phenolic resin) and then prepared metallographically (mechanical

TABLE II. MOLYBDENUM'S SPS SINTERING PARAMETERS

\begin{tabular}{|l|c|c|c|}
\hline \multirow{2}{*}{ Sample } & \multicolumn{3}{|c|}{ Molybdenum sintering parameters } \\
\cline { 2 - 4 } & $\begin{array}{c}\text { Temperature } \\
\left({ }^{\circ} \boldsymbol{C}\right)\end{array}$ & $\begin{array}{c}\text { Holding Time } \\
(\text { min })\end{array}$ & $\begin{array}{c}\text { Relative Density } \\
(\%)\end{array}$ \\
\hline 1 & 1200 & 5 & 84.4 \\
\hline 2 & 1350 & 5 & 91.2 \\
\hline 3 & 1450 & 5 & 94.8 \\
\hline 4 & 1550 & 5 & 96.5 \\
\hline 5 & 1650 & 5 & 97.0 \\
\hline 6 & 1750 & 5 & 98.4 \\
\hline 7 & 1850 & 5 & 98.6 \\
\hline 8 & 1950 & 5 & 99.5 \\
\hline 9 & 1850 & 10 & 99.6 \\
\hline 10 & 1850 & 20 & 99.8 \\
\hline 11 & 1850 & 30 & 100 \\
\hline
\end{tabular}


grinding and polishing down to $0,05 \mu \mathrm{m}$ silica slurry). The samples were examined using optical and scanning electron microscopy (SEM). Energy dispersive X-ray spectroscopy (EDX) was used to identify the interface materials reaction.

\section{Mo powder Sintering}

The sintering of the molybdenum powder using a SPS is presented in details in [10]. Table II presents the relative density in function of sintering temperature, ranging from $1200{ }^{\circ} \mathrm{C}$ to $1950{ }^{\circ} \mathrm{C}$ with a holding (sintering) time ranging from 5 to $30 \mathrm{~min}$, under a fixed pressure of $77 \mathrm{MPa}$ and a fixed heating rate of $700{ }^{\circ} \mathrm{C} / \mathrm{min}$. A relative density of $100 \%$ is achieved at a sintering temperature of $1850{ }^{\circ} \mathrm{C}$ hold for $30 \mathrm{~min}$. Fig. 1 shows a cross-sectional optical micrograph of a bulk of molybdenum sintered at $1850{ }^{\circ} \mathrm{C}$ for $5 \mathrm{~min}$. The sample was chemically etched in $\mathrm{H}_{2} \mathrm{SO}_{4}: \mathrm{HNO}_{3}: \mathrm{H}_{2} \mathrm{O}$ (1:1:3) solution. It shows that there are almost no pores between grains of Mo.

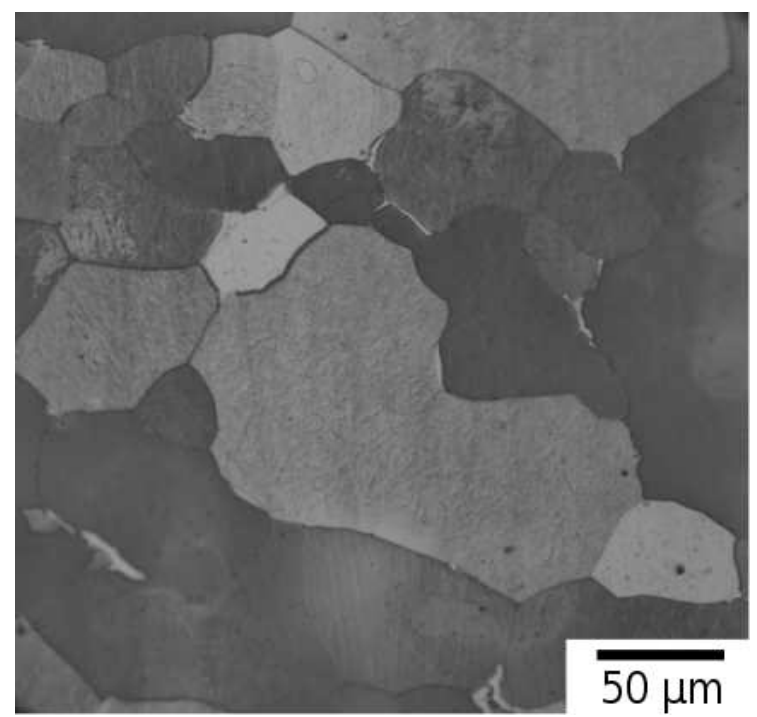

Figure 1. Cross-sectional optical micrograph of bulk molybdenum

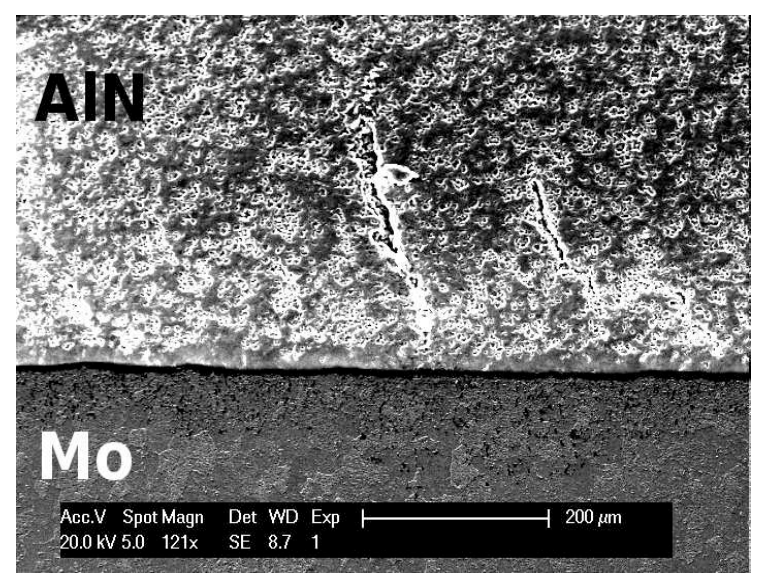

Figure 2. Cross-sectional SEM photo of Mo/AlN interface

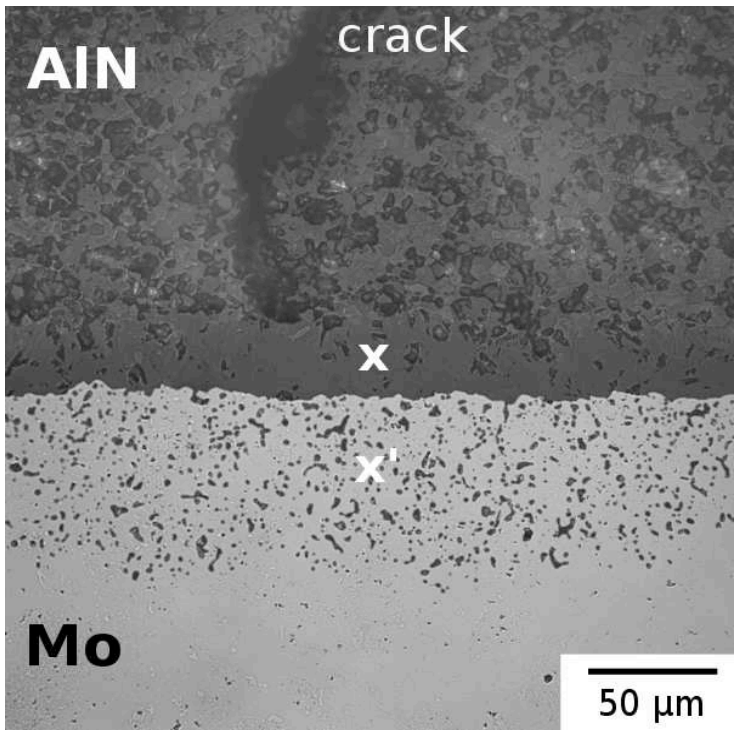

Figure 3. Optocal microscope observation of the cross section of an AlN/Mo assembly. The "X"s indicate zones where EDX measurements were performed to analyze the chemical species present close to the interface

\section{Molybdenum / AlN assembly}

First, Molybdenum powder was sintered on a disk of AIN with thickness of $633 \mu \mathrm{m}$ using a $20 \mathrm{~mm}$ diameter's graphite die. We achieved a good assembly at the Mo/AlN interface for all samples. However, we noticed that the AIN layer fissured during the process. We attributed these cracks to the pressure applied by the SPS press. However, even at the lowest force setting $(5 \mathrm{kN}$, or $16 \mathrm{MPa}$ for a $20 \mathrm{~mm}$ sample diameter), cracks occurred. To avoid cracks, we used a disk of AlN with a higher thickness $(1.27 \mathrm{~mm})$, and placed it in a $40 \mathrm{~mm}$ diameter graphite die.

Fig. 2 shows a cross-sectional SEM photo of a Mo/AlN interface, for a sample assembled at $1850{ }^{\circ} \mathrm{C}$ with a force of 5 $\mathrm{kN}$ applied by the press (which corresponds to $4 \mathrm{MPa}$ in the $40 \mathrm{~mm}$ diameter die) with a holding time of $5 \mathrm{~min}$. It shows the sublimation of a layer of AlN occurring during the sintering. Moreover, small cracks can also be seen, but they are limited to the neighbourhood of the interface. A close-up is given in fig.3. Some EDX characterization were performed and, shows that at the x marks, we have an area in the ceramic layer rich in aluminium. This means that some reaction occurred at the AlN/Mo interface.

\section{DISCUSSION}

SPS allows for molybdenum sintering at "low" temperature (much lower that the melting point of molybdenum, at $2623^{\circ} \mathrm{C}$ ), with a high density (up to $100 \%$ ). Using the same equipment, a bond between molybdenum and aluminium nitride was successfully achieved, although some sublimation of AlN occurred. To reduce this effect, we can reduce the sintering temperature. The microstructure at the interface between Mo and AlN must be conducted in order to get a better insight of the phenomena that have taken place. Moreover, a bending test will now be carried out to ensure that the bonding strength is good enough for our applications. At 
last but not least an electrical characterization (dielectric strength) is required as well as a thermal cycling to study the reliability of the substrate.

\section{CONCLUSION}

Molybdenum powder was sintered to bulk using a Spark Plasma Sintering technique. This technique allows to achieve full densification in a few minutes. Molybdenum powder was sintered on disks of $\mathrm{AlN}$, at $1850{ }^{\circ} \mathrm{C}$ for $5 \mathrm{~min}$ with a pressure of $4 \mathrm{MPa}$, showing a chemical reaction at interface level. Small cracks can also be seen, but they are limited to the neighbourhood of the interface.

\section{ACKNOWLEDGMENT}

The authors would like to thank the INSA de Lyon for their financial support of this work under the BQR grant. They are also pleased to acknowledge important contributions used in the body of this work from G. Bonnefont and F. Mercier from MATEIS for SPS processing.

\section{REFERENCE}

[1] C. Raynaud, D. Tournier, H. Morel, and D. Planson, "Comparison of high voltage and high temperature performances of wide bandgap semiconductors for vertical power devices," Diam. Rel. Mat., vol. 19, no. 1, pp. 1-6, 2010.

[2] C. Buttay et al., "State of the art of high temperature power electronics," Mat. Sci. Eng. B, vol. 176, no. 4, pp. 283-288, 2011.

[3] P. G. Neudeck, R. S. Okojie, and L.-Y. Chen, "High-temperature electronics - a role for wide bandgap semiconductors?," Proc. IEEE, vol. 90, no. 6, pp. 1065-1076, 2002.

[4] L. Dupont, S. Lefebvre, Z. Khatir, and S. Bontemps, "Evaluation of substrate technologies under high temperature cycling," 4th Int. Conf. Integ. Power Sys. (CIPS), pp. 1-6, 2006.

[5] M. Bratcher, R. J. Yoon, and B. Whitworth, "Aluminium nitride package for high-temperature applications," 3rd Int. Hi. Temp. Elec. Conf., Alburquerque, NM, pp. P95-P100, 1996.

[6] T. Martin and T. Bloom, "High-temperature aluminium nitride packaging," 3rd Int. Hi. Temp. Elec. Conf., Alburquerque, NM, pp. 103$108,1996$.

[7] N. Chasserio, S. Guillemet-Fritsch, T. Lebey, and S. Dagdag, "Ceramic substrates for high-temperature electronic integration," J. Elec. Mat., vol. 38, no. 1, pp. 164-174, 2009.

[8] L.-Y. Chena, R. S. Okojiea, P. G. Neudecka, G. W. Huntera, and S.-T. T. Lin, "Material system for packaging $500^{\circ} \mathrm{C} \mathrm{SiC} \mathrm{microsystems,"} \mathrm{Mat.}$ Res. Soc. Symp. Proc., vol. 682, p. N4.3.1-N4.3.12, 2001.

[9] E. Savrun and C. Toy, "An aluminum nitride package for $600{ }^{\circ} \mathrm{C}$ and beyond,” 4th Int. Hi. Temp. Elec. Conf. (HITEC), pp. 265-268, 1998.

[10] B. Mouawad, M. Soueidan, D. Fabrègue, C. Buttay, V. Bley, and B. Allard, "Full densification of Molybdenum powders using Spark Plasma Sintering", Metal. Mat. Trans A, in press 